\title{
Congenital Malformations of the Reproductive Tract in a Patient with Poland Syndrome: Is There a Connection?
}

\author{
Tian Meng Ming Bai Ru Zhao \\ Department of Plastic and Aesthetic Surgery, Peking Union Medical College Hospital, Beijing, China
}

\section{Established Facts}

- Poland syndrome and Müllerian duct agenesis (Mayer-Rokitansky-Küster-Hauser-like syndrome) are two rare congenital anomalies with unclear etiology.

\section{Novel Insights}

- This is a report of Poland syndrome associated with Müllerian duct agenesis. This condition is extremely rare.

- We can speculate that these two congenital anomalies that arose from distant sites may be interrelated.

- More cases and further studies are required to help delineate the pathogenesis of these syndromes.

\section{Keywords}

Pathogenesis - Poland syndrome - Breast aplasia · Müllerian duct abnormality · Mayer-Rokitansky-KüsterHauser syndrome · Hyperandrogenism · WNT4 gene

\section{Summary}

Background: Poland syndrome and Müllerian duct agenesis (Mayer-Rokitansky-Küster-Hauser(MRKH)-like syndrome) are two rare congenital anomalies with unclear etiology. Case Report: An 18-year-old female presented with hypoplasia of the left pectoralis muscles and subcutaneous tissue, hypoplasia of the left breast and nipple, and dextrocardia, typical in those with a severe form of Poland syndrome. She also showed aplasia of the vagina and uterus, bilateral ovarian agenesis, and hyperandrogenism, presenting as MRKH-like syndrome. Conclusion: It is plausible to assume that these two congenital anomalies which arose from distant sites may be interrelated. More cases and further studies will certainly help delineate the pathogenesis of these syndromes.

(c) 2017 S. Karger GmbH, Freiburg

\section{Introduction}

Poland syndrome is a sporadically occurring rare congenital anomaly characterized by unilateral thoracic musculoskeletal disorders with or without ipsilateral hand abnormalities [1]. So far, its etiology is still being hypothesized. A wide spectrum of phenotypes of Poland syndrome exists in the literature. In terms of the chest wall hypoplasia, absence of the sternocostal head of the pectoralis major muscle is present in most cases; therefore, this has been defined as the major diagnostic criterion. Other manifestations, defined as minor criteria of the syndrome, include varying degrees of hypoplasia of the pectoralis minor muscle, the rib cage, serratus anterior, latissimus dorsi, subcutaneous tissue of the chest wall, breast, and nipple. The incidence of this syndrome has been reported to be in the range of $1: 7,000-100,000$, with a male predominance (male-to-female ratio 2-3:1).

The Mayer-Rokitansky-Küster-Hauser (MRKH) syndrome is also a rare congenital anomaly, with an incidence rate of approximately 1 : 4,500 females [2]. It is characterized by the congenital absence of the upper part of the vagina associated with a variable abnormality of the uterus in women showing a normal 46,XX karyotype [3,4].

\section{KARGER}

(๑) 2017 S. Karger GmbH, Freiburg
Ru Zhao, MD

Department of Plastic and Aesthetic Surgery

Peking Union Medical College Hospital

No.1 Shuaifuyuan Wangfujing Dongcheng District, Beijing 100730, China

xhzr_pumc@163.com 


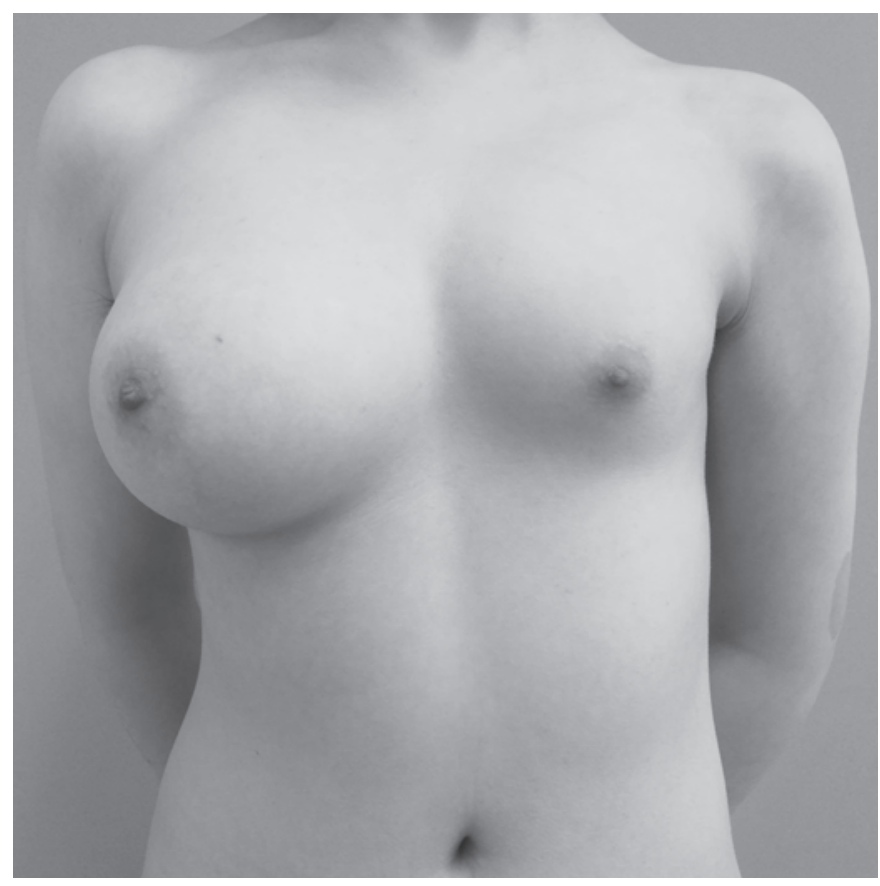

Fig. 1. Photograph of our patient with left-sided Poland syndrome showing hypoplasia of the left breast and nipple.

The exact mechanisms of female reproductive tract development and regulation are complex and remain unclear. In our study, we report on congenital malformations of the reproductive tract in an 18-year-old girl with typical Poland syndrome.

\section{Case Report}

An 18-year old female patient with Poland syndrome was admitted to our department complaining of hypoplasia of the left breast. She also reported to have primary amenorrhea, and a gynecologic examination revealed aplasia of the vagina and uterus. There was no family history of Poland syndrome or any other congenital disease. She is an only child.

The patient showed normal female appearance and was of normal intelligence. Physical examination disclosed normal height $(164 \mathrm{~cm})$, weight $(52 \mathrm{~kg})$, and body mass index $\left(19.33 \mathrm{~kg} / \mathrm{m}^{2}\right)$; hypoplasia of the left breast and nipple (fig. 1), left pectoralis muscles, and subcutaneous tissue; dextrocardia; pubic hair of the adult-female type, and normal size of the labia and clitoris. The vaginal pouch was small.

Chest X-ray, computed tomography (CT), and 3-dimensional reconstruction of the thorax showed dextrocardia, depression of the left thorax, mediastinum shifted to the right, left-sided aplasia of pectoral muscles and breast, and scoliosis (figs. 2, 3).

Doppler ultrasonography of the uterus and adnexa showed undetectable ovaries; there was a small strip-shaped hypoechoic area behind the bladder without endometrium-like echogenicity, which suggested a possible primordial uterus (fig. 4).

Pelvic CT also revealed an obscure uterus and ovaries (fig. 5).

Echocardiogram (ECG) showed the heart had shifted to the right side; cardiac function was normal.

Chromosomal analysis showed a normal 46,XX karyotype. Sex hormone examination revealed the following: follicle-stimulating hormone $4.50 \mathrm{IU} / \mathrm{l}$ (follicular phase: $<10$, ovulatory phase: $4.54-30.34$, luteal phase: $1.65-9.66$, menopause: $>40$ ), estradiol (E2) $71.09 \mathrm{pg} / \mathrm{ml}$ (follicular phase: $27-122$, ovulatory
Fig. 2. Computed tomography of the chest showing dextrocardia, depression of the left thorax, mediastinum shifted to the right, and aplasia of pectoral muscles and breast on the left.

Fig. 3. 3-dimensional reconstruction of the thorax showing aplasia of ribs III-V, rotation of the sternum, and scoliosis.

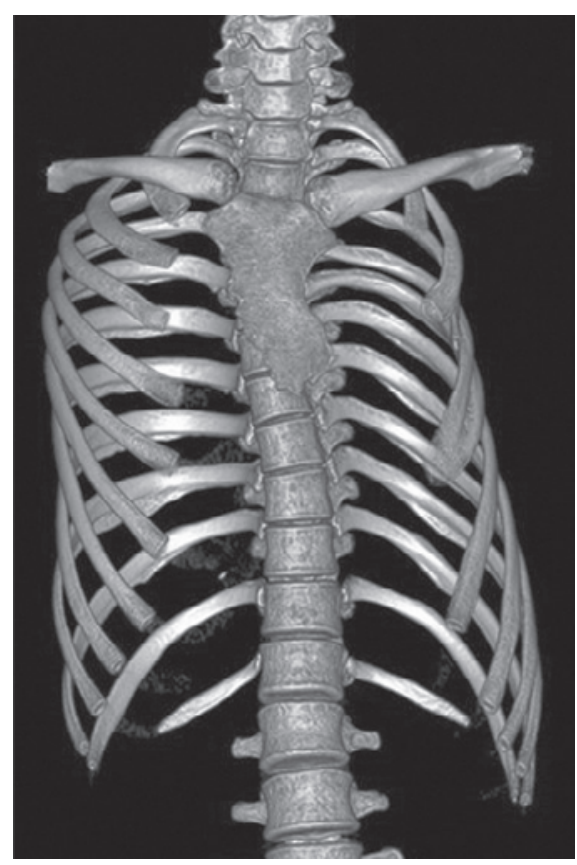

Fig. 4. Doppler ultrasonography of uterus and adnexa showing undetectable ovaries small hypoechoic area behind the bladder without endometrium like echogenicity (arrow).

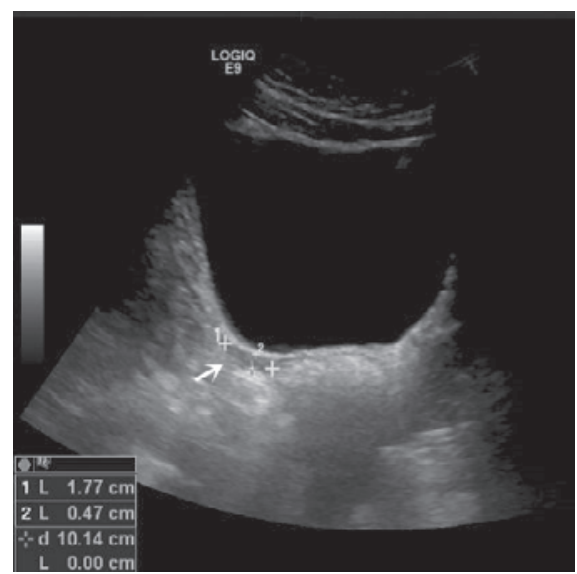

phase: 95-433, luteal phase: 49-291, menopause: $<40)$, progestogen $0.42 \mathrm{ng} / \mathrm{ml}$ (follicular phase: $0.38-2.28$, ovulatory phase: $0.93-2.23$, luteal phase: $5.16-$ 29.26, menopause: $<0.78$ ), luteinizing hormone $3.57 \mathrm{IU} / \mathrm{l}$ (follicular phase: $2.12-10.89$, ovulatory phase: $19.18-103.03$, luteal phase: $1.20-12.86$, menopause: $10.87-58.64)$, prolactin $7.13 \mathrm{ng} / \mathrm{ml}(<30)$, testosterone $0.81 \mathrm{ng} / \mathrm{ml}(0.1-$ $0.75)$, and dehydroepiandrosterone sulfate $363.6 \mu \mathrm{g} / \mathrm{dl}(51-321)$. 

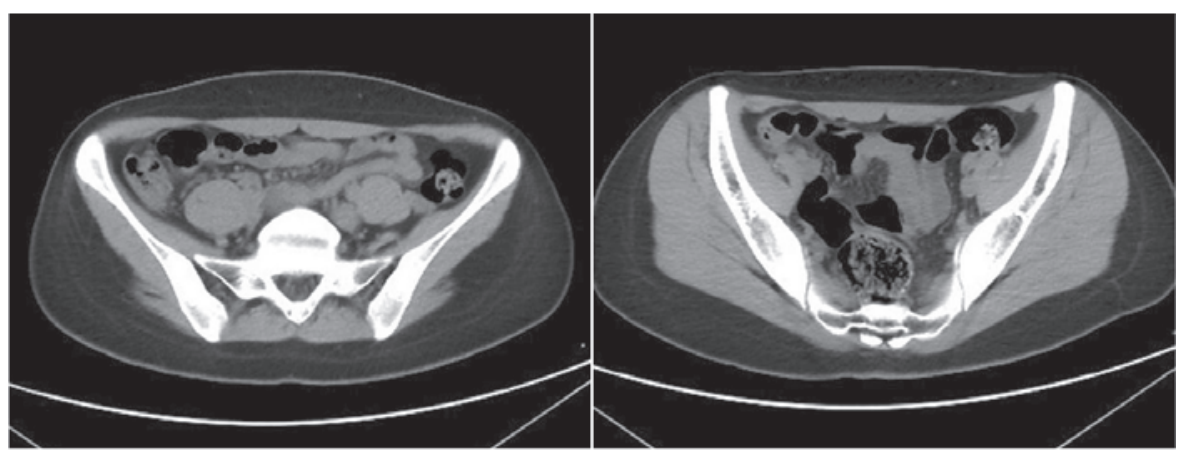

Fig. 5. Computed tomography of the pelvis
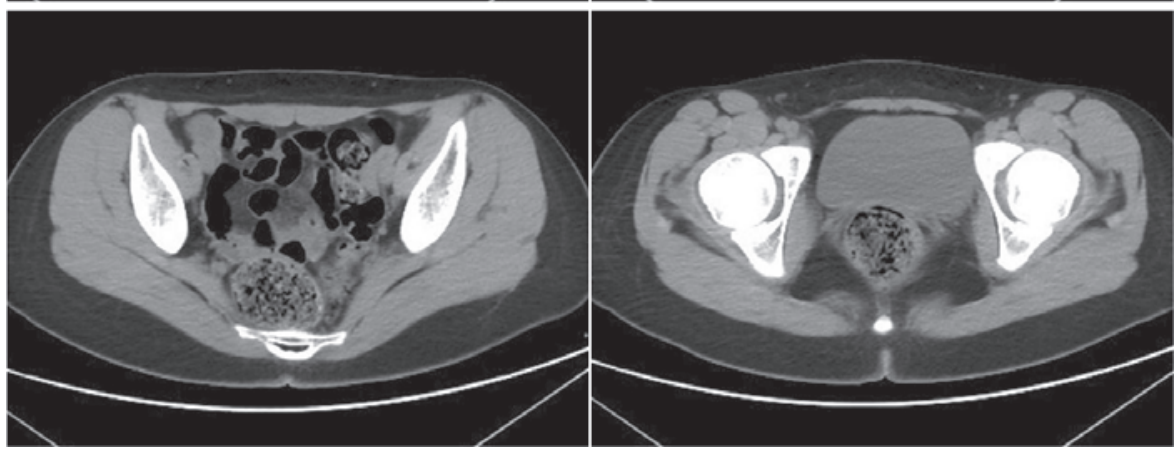

showing obscure uterus and ovaries.

\section{Discussion}

The etiology of Poland syndrome remains unclear. Most cases suggest that this syndrome is of sporadic occurrence. So far, the explanation of its etiology is still being developed. The prevailing theory is the 'subclavian artery blood supply disruption sequence': that is, the interruption of the early embryonic blood supply in the subclavian artery and/or its branches, eventually leading to hypoplasia of the ipsilateral chest wall and/or hand abnormalities. However, other factors, such as genetic or chromosomal defects, abnormal migration of fetal mesoderm, or intrauterine environmental effects, cannot be excluded [5].

Our patient showed absence of the sternocostal part of the pectoralis major muscle, absence of the pectoralis minor muscle, a sunken left chest wall, hypoplasia of the left breast, and dextrocardia, which meet the typical diagnostic criteria of a severe form of Poland syndrome. Of special interest is that our patient also showed signs of aplasia of the upper part of the vagina and the uterus, bilateral ovarian agenesis, and hyperandrogenism. We reviewed the literature and found that no similar cases exist. Our patient's situation is extremely rare.

The phenotype of our patient was analyzed for MRKH syndrome, the etiology of which remains unknown. To determine the pathogenesis of this syndrome, some candidate genes have been studied, such as the genes coding for galactose-1-phosphate uridyl transferase $(G A L T)$ [6], the cystic fibrosis transmembrane regulator chloride channel (CFTR) [7], and the anti-Müllerian hormone $(A M H)$ and its receptor (AMHR2) [8, 9], as well as several developmental genes such as Wilms tumor 1 (WT1), paired box gene 2 (PAX2) [10], homeobox genes class a (HOXA) [11], or the testisspecific protein 1-Y-gene (TSPY) [12]; however, none of these genes were found to be implicated in the pathogenesis of MRKH syn- drome. To date, only the WNT4 gene, which is considered to be a crucial signaling molecule for female sexual development, has been suggested to contribute to Müllerian duct abnormalities in women as well as in mice models [13-17]. It has been reported that women with an identified WNT4 gene mutation manifested a phenotype characterized by Müllerian duct agenesis and clinical or biologic evidence of hyperandrogenism. Thus, this phenotype is regarded as distinct from the classic MRKH syndrome and classified as atypical MRKH syndrome or 'WNT4 defects'. Hence, our patient, who displayed aplasia of the uterus and the upper part of the vagina accompanied by bilateral ovarian agenesis and hyperandrogenism, should be assumed more precisely as an MRKH-like phenotype.

The etiologies of Poland syndrome and MRKH-like syndrome remain elusive. Previous studies have shown an association between MRKH and other malformations, such as MURCS (Müllerian, renal, cervicothoracic somite abnormalities) syndrome and possibly Poland syndrome $[18,19]$. However, the correlation between such MRKH-like phenotypes and a specific genotype is still difficult to establish. Current findings now support the hypothesis of a polygenic/multifactorial cause. For a long time, the prevailing theory of the etiology of Poland syndrome was that of the 'subclavian artery blood supply disruption'; however, evidently, this does not explain all the situations encountered in Poland syndrome. A great number of reports described an increased incidence of malignancies in people with Poland syndrome, including leukemia, nonHodgkin's lymphoma, breast cancer [20,21], lung cancer [22], and leiomyosarcoma. Also, some case reports showed that congenital anomalies at distant sites coexisted with Poland syndrome. A recent study reported that concomitant congenital malformations are present in about $50 \%$ of women with MRKH syndrome [23]. Thus, other factors such as autosomal dominant inheritance, gene defects, or environmental effects may play a role in Poland syn- 
drome. With regard to our patient, although we cannot exclude the possibility that her two conditions co-occurred by coincidence, it is more reasonable to define her case based on the monophyletic theory and assume that the two congenital anomalies which arose from distant sites may be interrelated. Whether there are underlying genetic abnormalities or contributing developmental or environmental factors is an important issue to resolve. Any new discoveries in either syndrome may lead to important clues to the causes of the other. We believe that cases similar to our patient may be reported in the future. More cases and further studies will certainly help to delineate the pathogenesis of these syndromes.

\section{Disclosure Statement}

The authors declared that they have no conflicts of interest related to this work.

\section{References}

1 Fokin AA, Robicsek F: Poland's syndrome revisited. Ann Thorac Surg 2002;74:2218-2225.

2 Folch M, Pigem I, Konje JC: Mullerian agenesis: etiology, diagnosis, and management. Obstet Gynecol Surv 2000;55:644-649.

3 Morcel K, Camborieux L; Programme de Recherches sur les Aplasies M, Guerrier D: Mayer-RokitanskyKuster-Hauser (MRKH) syndrome. Orphanet J Rare Dis 2007;2:13.

4 Pittock ST, Babovic-Vuksanovic D, Lteif A: MayerRokitansky-Kuster-Hauser anomaly and its associated malformations. Am J Med Genet A 2005;135:314-316.

5 Shalev SA, Hall JG: Poland anomaly - report of an unusual family. Am J Med Genet A 2003;118A:180-183.

6 Klipstein S, Bhagavath B, Topipat C, Sasur L, Reindollar RH, Gray MR: The N314D polymorphism of the GALT gene is not associated with congenital absence of the uterus and vagina. Mol Hum Reprod 2003;9: 171-174.

7 Timmreck LS, Gray MR, Handelin B, Allito B, Rohlfs E, Davis AJ, Gidwani G, Reindollar RH: Analysis of cystic fibrosis transmembrane conductance regulator gene mutations in patients with congenital absence of the uterus and vagina. Am J Med Genet A 2003;120A:72-76.

8 Oppelt P, Strissel PL, Kellermann A, Seeber S, Humeny A, Beckmann MW, Strick R: DNA sequence variations of the entire anti-Mullerian hormone (AMH) gene promoter and $\mathrm{AMH}$ protein expression in patients with the Mayer-Rokitanski-Kuster-Hauser syndrome. Hum Reprod 2005;20:149-157.

9 Josso N, Picard JY, Rey R, di Clemente N: Testicular anti-Mullerian hormone: history, genetics, regulation and clinical applications. Pediatr Endocrinol Rev 2006; 3:347-358.
10 Wang P, Zhao H, Sun M, Li Y, Chen ZJ: PAX2 in 192 Chinese women with Mullerian duct abnormalities: mutation analysis. Reprod Biomed Online 2012;25: 219-222.

11 Burel A, Mouchel T, Odent S, Tiker F, Knebelmann B, Pellerin I, Guerrier D: Role of HOXA7 to HOXA13 and PBX1 genes in various forms of MRKH syndrome (congenital absence of uterus and vagina). J Negat Results Biomed 2006;5:4

12 Plevraki E, Kita M, Goulis DG, Hatzisevastou-Loukidou H, Lambropoulos AF, Avramides A: Bilateral ovarian agenesis and the presence of the testis-specific protein 1-Y-linked gene: two new features of MayerRokitansky-Kuster-Hauser syndrome. Fertil Steril 2004;81:689-692.

13 Biason-Lauber A, Konrad D, Navratil F, Schoenle EJ: A WNT4 mutation associated with Mullerian-duct regression and virilization in a 46,XX woman. N Engl J Med 2004;351:792-798.

14 Philibert P, Biason-Lauber A, Rouzier R, Pienkowski C, Paris F, Konrad D, Schoenle E, Sultan C: Identification and functional analysis of a new WNT4 gene mutation among 28 adolescent girls with primary amenorrhea and Mullerian duct abnormalities: a French collaborative study. J Clin Endocrinol Metab 2008;93:895-900.

15 Biason-Lauber A, De Filippo G, Konrad D, Scarano G, Nazzaro A, Schoenle EJ: WNT4 deficiency - a clinical phenotype distinct from the classic Mayer-RokitanskyKuster-Hauser syndrome: a case report. Hum Reprod 2007;22:224-229.
16 Philibert P, Biason-Lauber A, Gueorguieva I, Stuckens C, Pienkowski C, Lebon-Labich B, Paris F, Sultan C: Molecular analysis of WNT4 gene in four adolescent girls with Mullerian duct abnormality and hyperandrogenism (atypical Mayer-Rokitansky-Kuster-Hauser syndrome). Fertil Steril 2011;95:2683-2686.

17 Sultan C, Biason-Lauber A, Philibert P: Mayer-Rokitansky-Kuster-Hauser syndrome: recent clinical and genetic findings. Gynecol Endocrinol 2009;25:8-11.

18 Oppelt P, Renner SP, Kellermann A, Brucker S, Hauser GA, Ludwig KS, Strissel PL, Strick R, Wallwiener D, Beckmann MW: Clinical aspects of Mayer-RokitanskyKuester-Hauser syndrome: recommendations for clinical diagnosis and staging. Hum Reprod 2006;21:792-797.

19 Shivalingappa SS, Shetty SB: Mayer-RokitanskyKüster-Hauser (MRKH) syndrome with unilateral pulmonary agenesis - a rarity indeed: radiologic review. BJR Case Rep 2015;2015:20150157.

20 Zhang F, Qi X, Xu Y, Zhou Y, Zhang Y, Fan L, Zhong L, Yang X, Jiang J: Breast cancer and Poland's syndrome: a case report and literature review. Breast J 2011;17:196-200.

21 Tamiolakis D, Venizelos D, Antoniou C, Tsiminikakis $\mathrm{N}$, Alifieris E, Papadopoulos N: Breast cancer development in a female with Poland's syndrome. Onkologie 2004;27:569-571.

22 Ahn MI, Park SH, Park YH: Poland's syndrome with lung cancer. A case report. Acta Radiol 2000;41:432434

23 Kapczuk K, Iwaniec K, Friebe Z, Kedzia W: Congenital malformations and other comorbidities in 125 women with Mayer-Rokitansky-Kuster-Hauser syndrome. Eur J Obstet Gynecol Reprod Biol 2016;207:45-49. 